Faltenglättung durch Muskelentspannung

\title{
Topischer Wirkstoff reduziert Faltentiefe
}

Nach Jahren der Entwicklung stellt SQOOM die kosmetische Weltneuheit SQOOM xcential SkinCare vor. Die kosmetische Innovation Argireline ${ }^{\circledR}$, der neu entwickelten Anti-Aging Pflegecremes ermöglicht es, den Zeichen der Zeit sanft und nebenwirkungsfrei zu begegnen.

Hochwirksame Inhaltsstoffe wie Argireline ${ }^{\circledast}$, Traubenkernöl und Resveratrol sorgen für eine Verbesserung und gleichzeitige Verjüngung des Teints. Die Regenerationskraft von Traubenkernöl - auch Vitamin F genannt, erhält durch ihren sehr hohen Anteil an mehrfach ungesättigten Fettsäuren die hauteigene Lipidschicht flexibel und elastisch.

Ein weiterer Wirkstoff namens Reservatrol wird aus den Schößlingen des Weines gewonnen. Die Antioxidantien schützen die Haut vor schädlichen Umwelteinflüssen und haben außerdem eine zellaufbauende Wirkung.

\section{Patentierter Wirkstoff wirkt wie Botulinumtoxin}

Argireline $^{\circledast}$ verringert die Ausschüttung von Acetylcholin. Folge: Der Muskel entspannt sich und die Falten glätten sich nach und nach. Aus diesem Grund wird Argireline ${ }^{\varpi}$ auch als Botox-Ersatzstoff gehandelt. Der Vorteil ist, dass es nicht gespritzt werden muss. Außerdem ist es nicht giftig und verursacht keinerlei toxische Reaktionen. SQOOM xcential SkinCare reduziert die Aktivität der Muskeln und entspannt diese nachhaltig. Umfassende Anwenderstudien belegen die positive Wirkung dieser weltweit einzigartigen Formel. Sie basiert auf natürlichen Aminosäuren, wie sie auch im menschlichen Körper vorkommen. Das Ergebnis ähnelt einer Faltenunterspritzung. Studien und Lasermessungen zeigen, dass Argireline die Faltentiefe nachhaltig um bis zu 50\% reduziert.

Wie alle Produkte von Schick Medical werden auch die Produkte der SQOOM Serie nicht an Tieren getestet. Von Inhaltsstoffen bis Verpackung wird ausschließlich in Deutschland produziert.

Nach Informationen der Schick Medical GmbH

\section{Placebokontrollierte Studie zu Haarausfall}

\section{Wirkstoffkomplex mit Taurin verbessert Haardichte}

Auf dem EADV in Lissabon präsentierte das Team der dermatologischen Forschung von L'Oreal und der Nestle Ernährungsforschung aktuelle Studien zu seiner Innéov-Serie -wie der Vergleich zu Placebo bei Innéov Haarfülle.

Das Nahrungsergänzungsmittel Innéov Haarfülle enthält den patentierten Wirkstoffkomplex aus Taurin und Zink. Taurin lagert sich direkt in der Haarwurzel an und entfaltet dort seine schützende Wirkung. “Zusätzlich zu dieser Wirkstoffkombination (in einer grünen Tablette) versorgt die violette Kapsel der Kombipackung die Haarwurzeln mit Omega 3- und Omega 6-Fettsäuren, um das Wachstum kräftiger und dichter Haare zu fördern. Katechine aus grünem Tee und Traubenkern-Extrakten fördern die Mikrozirkulation, wodurch das Haar besser mit Nährstoffen versorgt werden kann“, erläuterte Prof. Dr. Ulrike Heinrich vom Dermatronnierinstitut in Witten das Prinzip von Innéov Haarfülle auf einem Pressegespräch in Lissabon.

\section{Wirksamkeit bereits nach} zwölf Wochen

Heinrich präsentierte eine doppelblindplacebokontrollierte Haarstudie, an der 160 weibliche Probanden mit Haarausfall teilnahmen. Die Probandinnen waren zwischen 30 und 50 Jahre alt und wiesen eine Haardichte kleiner 250 Haare pro $\mathrm{cm}^{2}$ auf. Mittels Trichoscan ${ }^{\circledast}$ sowie klinischer Auswertung und Selbstbeurteilung der Studienteilnehmer wurde zum Zeitpunkt Null sowie nach dreimonatiger und sechsmonatiger Einnahme des Wirkstoffkomplexes die Haarfülle bestimmt. Das Ergebnis: Bereits nach 12 Wochen konnte eine Verringerung des Haarausfalls sowie eine Zunahme der Haarstärke gemessen werden. „Die Haardichte stieg signifikant von 176 pro $\mathrm{cm}^{2}$ zum Zeit-

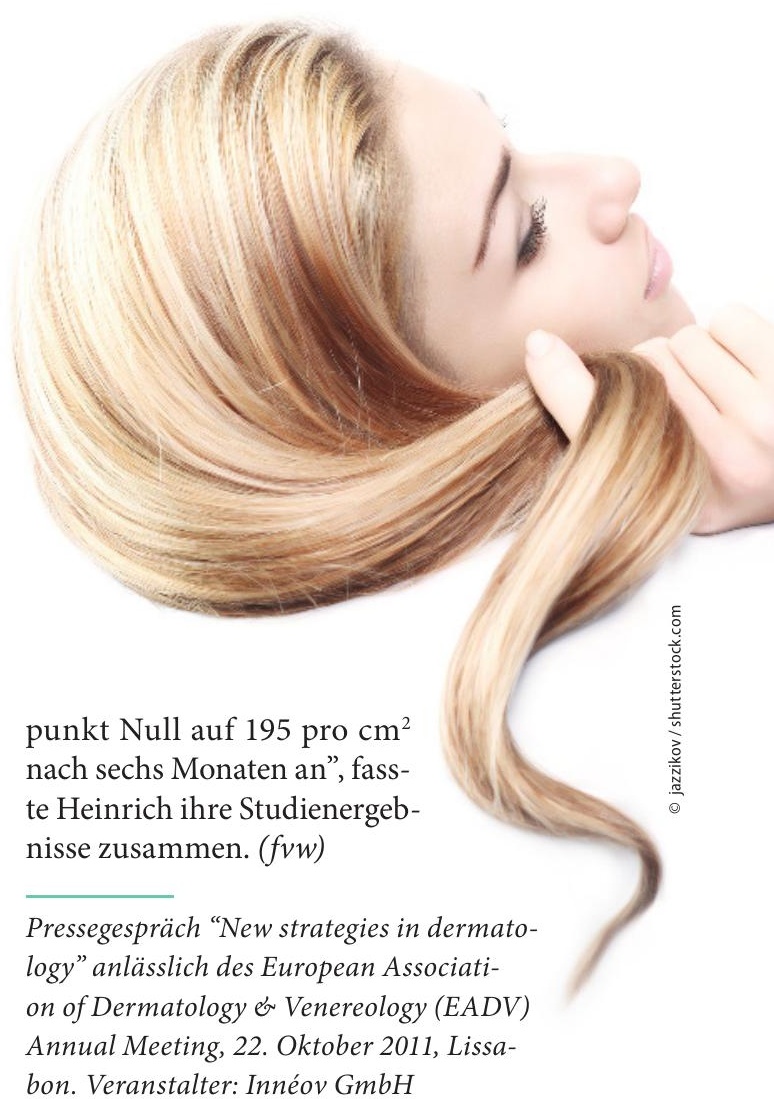

bon. Veranstalter: Innéov GmbH 